\title{
Impaired final follicular maturation in heifers after superovulation with recombinant human FSH
}

\author{
M. Takagi ${ }^{1,2}$, I. H. Kim¹,3, F. Izadyar ${ }^{1}$, P. Hyttel ${ }^{4}$, M. M. Bevers ${ }^{1}$, \\ S. J. Dieleman ${ }^{1}$, P. J. M. Hendriksen ${ }^{1}$ and P. L. A. M. Vos ${ }^{1 *}$ \\ ${ }^{1}$ Department of Farm Animal Health, Faculty of Veterinary Medicine, Utrecht University, \\ Yalelaan 7, 3584 CL Utrecht, The Netherlands; ${ }^{2}$ Faculty of Veterinary Medicine, Obihiro \\ University of Agriculture and Veterinary Medicine, Obihiro 080-0835, Hokkaido, Japan; \\ ${ }^{3}$ Department of Veterinary Medicine, Chungbuk National University, South Korea; and \\ ${ }^{4}$ Department of Anatomy and Physiology, Royal Veterinary and Agricultural University, \\ Frederiksberg C, Denmark
}

The aim of this study was to investigate whether human FSH without contaminating LH can exert a normal superovulation response in cows. One group of heifers $(n=9)$ was stimulated with recombinant human $\mathrm{FSH}$ (rhFSH), an FSH source without any LH activity, and another group $(n=9)$ was treated with equine chorionic gonadotrophin (eCG), an FSH source with high LH activity. Daily transrectal ultrasonography showed that eCG- and rhFSH-stimulated heifers ( $n=9$ per group) had the same follicular growth characteristics and equal numbers of follicles $>8 \mathrm{~mm}$ in diameter after 3 days of stimulation. The treatment groups differed considerably in steroid production: rhFSH-treated heifers produced much lower oestradiol concentrations than did eCG-stimulated heifers during the first days of stimulation and much lower progesterone concentrations in the period after the $\mathrm{LH}$ surge. During the $27-35 \mathrm{~h}$ after prostaglandin injection,
rhFSH-treated heifers had fewer LH pulses than did eCGtreated heifers $(0.3$ versus 3.0 per heifer, respectively; $n=3$ per group). All rhFSH-treated heifers $(n=6)$ underwent a preovulatory LH surge, but this occurred significantly later than in the eCG-treated heifers $(n=4$; $39.4 \pm 1.9 \mathrm{~h}$ versus $47.1 \pm 1.5 \mathrm{~h}$ in $\mathrm{rhFSH}$ - and eCGtreated heifers, respectively). Multiple ovulations occurred in only three of six rhFSH-treated heifers, but in all four eCG-treated heifers with an LH surge. At $24 \mathrm{~h}$ after the $\mathrm{LH}$ surge, the percentage of metaphase II stage oocytes with cortical granules distributed close to the oolemma was significantly lower in the rhFSH group $(7.3 \%)$ than in the eCG group $(55.9 \%)$. In conclusion, final follicular maturation is impaired in heifers treated with $\mathrm{rhFH}$, which might be due to the combination of a lack of $\mathrm{LH}$ activity in the gonadotrophin preparation and the severe suppression of LH pulsatility.

\section{Introduction}

Despite the recent development of the technology of in vitro production of embryos, superovulation by injection of exogenous gonadotrophin is still the fundamental method to produce in vivo derived embryos for embryo transfer in cattle. However, the yield and quality of the embryos raised after superovulation are variable and unpredictable owing to variations in ovarian response, fertilization rate and embryo development (Boland et al., 1991). As well as cow factors, such as genetic background, age, breed, reproductive and lactation status, many other factors are assumed to contribute to this variability (Hasler et al., 1983; Donaldson, 1984a,b; Lerner et al., 1986). An important cause of the relatively low efficiency of superovulation are disorders in preovulatory development (Monniaux et al., 1984; Callesen

*Correspondence

Email: P.L.A.M.Vos@vet.uu.nl et al., 1986). The preovulatory-sized follicles that develop after gonadotrophin stimulation have a high incidence of asynchrony between follicular and oocyte maturation (matured oocytes within unmatured follicles or vice versa) (Hyttel et al., 1986; Callesen et al., 1987; de Loos et al., 1991). The causes of these disorders in preovulatory development are still unclear. One possibility is that part of the follicles in which growth is stimulated by the gonadotrophin consists of rescued atretic follicles that remain aberrant. Another possibility is related to the relatively short time interval between luteolysis and occurrence of the $\mathrm{LH}$ surge in cows stimulated by gonadotrophin compared with unstimulated cows (Bevers and Dieleman, 1987). In addition, several studies have shown that there is a difference in LH pulse frequency between unstimulated and gonadotrophin-stimulated cows (Bevers et al., 1989; Ben Jebara et al., 1994). These events might result in part of the follicles being incompletely matured to respond properly to the $\mathrm{LH}$ surge.

The variability in the $\mathrm{FSH}: \mathrm{LH}$ ratio of gonadotrophin 
preparations is considered to be an additional factor causing variability of superovulatory responses (Murphy et al., 1984; Donaldson and Ward, 1986). As commercially available $\mathrm{FSH}$ preparations are isolated from pituitary glands, such variations in $\mathrm{LH}: \mathrm{FSH}$ ratio are difficult to prevent. One approach used to circumvent this problem has been the isolation of pig FSH to high purity (Donaldson and Ward, 1986; Beckers, 1987; Herrler et al., 1991). However, superovulation of cattle with purified pig FSH led to varied responses from a complete lack of ovulation (Herrler et al., 1991) to a normal ovulation rate but with a small number of embryos (Schmidt et al., 1988) to a normal number of transferable embryos (Donaldson and Ward, 1986). These differences might be due to variations in the content of contaminating LH. More recently, this problem has been resolved by recombinant DNA technology, which enables production of $\mathrm{FSH}$ in the complete absence of contaminating $\mathrm{LH}$; this has been achieved for recombinant human FSH (rhFSH; Keene et al., 1989; Van Wezenbeek et al., 1990), recombinant bovine FSH (rbFSH; Wilson et al., 1993) and recombinant pig FSH (rpFSH; Inaba et al., 1997). The biological activities of these recombinant $\mathrm{FSH}$ preparations are similar to those of the products extracted from pituitary glands (Mannaerts et al., 1991; Wilson et al., 1993; Inaba et al., 1997).

In human infertility clinics, rhFSH is used widely to stimulate multiple follicular development enabling retrieval of oocytes matured in vivo that are processed for either IVF or intracytoplasmic sperm injection (ICSI). rhFSH is more effective than urinary-derived $\mathrm{FSH}$ with respect to multiple follicular development and yield of oocytes without affecting the developmental competence of the oocytes (Mannaerts et al., 1991; Recombinant Human FSH Product Development Group, 1998; Frydman et al., 2000). Recombinant FSH has also been used for superovulation in cattle; rbFSH resulted in normal production of viable embryos, indicating that exogenous LH activity is not necessary for follicular maturation and ovulation in gonadotrophin-stimulated cattle (Wilson et al., 1993).

In both cows and humans, the information on the effect of recombinant FSH is limited mainly to the yield of embryos and oocytes. Very little is known about the effect of the absence of LH activity in gonadotrophin preparations on endocrinological responses and maturation of oocytes.

The aim of the present study was to acquire more insight into the effects of stimulation of cattle with rhFSH on: (i) follicular growth dynamics; (ii) occurrence of the $\mathrm{LH}$ surge; (iii) the pattern of preovulatory LH pulses; (iv) ovulation rate; (v) luteinization of follicles; and (vi) nuclear and cytoplasmic maturation of oocytes. Heifers were treated with rhFSH and a control group was treated with equine chorionic gonadotrophin (eCG), thus enabling a comparison to be made between gonadotrophin preparations without LH activity and those with a relatively high $\mathrm{LH}$ activity.

\section{Materials and Methods}

\section{Animals}

The study was performed from March to November 1998 using Holstein-Friesian heifers $(n=12)$, aged 18-22 months at the beginning of the experiments, which were housed indoors and were fed silage and concentrate. Normal cyclicity was confirmed by measuring the progesterone concentration in peripheral blood samples three times per week during the 3 weeks before the experiments started. The experiments were carried out in three different sessions (1-3). During session 1, the first group of six heifers was assigned randomly to $\mathrm{rhFSH}(n=3)$ and eCG $(n=3)$ groups for superovulation to study: (i) follicular development during gonadotrophin stimulation; (ii) ovulation rate; and (iii) plasma progesterone, oestradiol and LH concentrations. This session was repeated (session 2) with the change that the treatments were reversed between the two groups of heifers. Moreover, during session 2, the LH pulse frequency patterns in plasma were measured for each superovulatory treatment. In session 3, the second group of six heifers was stimulated with either $\operatorname{rhFSH}(n=3)$ or eCG $(n=3)$ and these heifers were ovariectomized at 24-26 h after the spontaneously induced preovulatory LH surge. The following factors were studied: (i) follicular development during gonadotrophin stimulation; (ii) plasma progesterone, oestradiol and LH concentrations; (iii) the status of oocyte nuclear and cytoplasmic maturation; and (iv) progesterone and oestradiol concentrations in the follicular fluid of large follicles.

\section{Synchronization and removal of dominant follicles}

Oestrous cycles were synchronized with Crestar (Intervet International BV, Boxmeer), which includes a $3 \mathrm{mg}$ norgestomet ear implant and an i.m. injection of $5 \mathrm{mg}$ oestradiol valerate and $3 \mathrm{mg}$ norgestomet given at the time of the implant insertion. The implants were removed after 9 days. Two days before removal, the heifers received a single i.m. injection of $10 \mathrm{mg}$ prostaglandin (Prosolvin; Intervet International BV) to ensure complete regression of the corpus luteum. Oestrus (day 0; experimental day 11) occurred a mean 2 days after removal of the implants. From day 3 after oestrus onwards, development of the follicular population was observed every 2 days by ultrasonography for detection of a corpus luteum and a dominant follicle. As the presence of a dominant follicle on the day of superovulation induction could suppress the response of the remaining follicle population (Bungartz and Niemann, 1994), all follicles $>5 \mathrm{~mm}$ in diameter, including the dominant follicle, were removed on day 8 by transvaginal ultrasound-guided follicle puncture according to Vos et al. (1994).

\section{Superovulation treatment}

Superovulation treatment was started at day 10 after oestrus in both the rhFSH and eCG groups. rhFSH (Puregon, 
Org 32489; NV Organon, Oss) was supplied as lyophilized powder in vials, each containing $166 \mathrm{iu} \mathrm{FSH}$ in vivo bioactivity. After reconstitution with solvent, rhFSH was stored at $4^{\circ} \mathrm{C}$ for the duration of the injection period. In the rhFSH group $(n=9$; sessions 1,2 and 3$), \mathrm{rhFSH}$ was administered i.m. in decreasing doses according to a schedule reported before for pig pituitary extract (Dieleman et al., 1989). rhFSH was administered twice a day at 07:00 $\mathrm{h}$ and 19:00 $\mathrm{h}$ in decreasing doses of 600, 500, 300 and 100 iu at days 10,11, 12 and 13, respectively. As the use of rhFSH for superovulation of cattle has not been reported previously, the initial administration dose of 3 iu rhFSH kg-1 per day and the total dose of rhFSH (3000 iu) were based on reported doses of human menopausal gonadotrophin for superovulation of cattle and rhFSH for human treatment (Out et al., 1998). During treatment with rhFSH, $15 \mathrm{mg}$ prostaglandin was injected i.m. on day 12 at 07:00 h, simultaneously with the fifth injection of rhFSH.

In the eCG group ( $n=9$; sessions 1, 2 and 3), 2500 iu eCG (Folligon; Intervet International BV) was administered i.m. to all animals on day 10 at $07: 00 \mathrm{~h}$ and $15 \mathrm{mg}$ prostaglandin was administered i.m. on day 12 at 07:00 h. The same batch of eCG was used for all heifers. These heifers were injected i.v. with a monoclonal antibody against eCG (Neutra-PMSG; Intervet International BV) $6 \mathrm{~h}$ after the peak of the LH surge (Dieleman and Bevers, 1987).

\section{Follicular development and hormonal response}

Follicular development, and progesterone, oestradiol and $\mathrm{LH}$ concentrations in peripheral blood during and after gonadotrophin treatment were compared in heifers treated with either rhFSH $(n=9)$ or eCG $(n=9)$. From day 10 to day 13 , individual follicles $>3 \mathrm{~mm}$ in diameter were identified on both ovaries using a linear array $7.5 \mathrm{MHz}$ ultrasound scanner (type SSD-210; Aloka, Tokyo). The sizes of the follicles were recorded as the mean of two perpendicular diameters of the antrum of the follicle as measured with built-in callipers. The accuracy between subsequent measurements was $\pm 1 \mathrm{~mm}$ for follicles $\leqslant 8 \mathrm{~mm}$ in diameter. The position of the follicles ( $>3 \mathrm{~mm}$ in diameter) on the ovaries was registered by photographs taken by video copy (type P60B; Mitsubishi, Tokyo). The follicles were classified into three categories: $<5 \mathrm{~mm}, 5-8 \mathrm{~mm}$ and $>8 \mathrm{~mm}$ in diameter; the category $>8 \mathrm{~mm}$ was defined as preovulatory-sized follicles (Vos et al., 1994). The same two operators undertook scanning for all days. The ovulation rate was determined for six heifers per group (sessions 1 and 2 ) on day 7 after oestrus either by palpation per rectum and ultrasonography $(n=6$; during session 1$)$ by four skilled technicians or after the animals were killed $(n=6$; during session 2). The numbers of corpora lutea and follicles $>8 \mathrm{~mm}$ in diameter on each ovary were recorded. The hormonal response was investigated further by comparing the pulsatile patterns of $\mathrm{LH}$ secretion during the follicular phase after prostaglandin injection in three heifers per group (session 2).
Oocyte maturation rate of preovulatory follicles and progesterone or oestradiol dominancy of follicular fluids

During session 3, rhFSH- $(n=3)$ and eCG- $(n=3)$ treated heifers were compared for the nuclear and cytoplasmic maturation status of oocytes, and progesterone or oestradiol dominancy (progesterone:oestradiol $>1$ or progesterone: oestradiol $<1$, respectively) of follicular fluids. The time of the $\mathrm{LH}$ surge was determined by measuring the $\mathrm{LH}$ concentration in plasma collected at $1 \mathrm{~h}$ intervals from $24 \mathrm{~h}$ after the prostaglandin injection onwards by a rapid radioimmunoassay. Exactly $24 \mathrm{~h}$ after the $\mathrm{LH}$ surge (around the expected time of ovulation), the ovaries of the heifers were recovered by ovariectomy as described by de Loos et al. (1991). Follicular fluid and oocytes were collected from individual non-atretic preovulatory follicles $(>8 \mathrm{~mm}$ in diameter) by aspiration. After retrieval of the oocytes, the follicular fluids were stored at $-25^{\circ} \mathrm{C}$ and progesterone and oestradiol concentrations were assessed by radioimmunoassay. Cumulus-oocyte complexes (COCs) were judged on cumulus expansion, the oocytes were freed subsequently from cumulus cells by vortexing for $3 \mathrm{~min}$ and were then fixed for $15 \mathrm{~min}$ in $2 \%(\mathrm{w} / \mathrm{v})$ paraformaldehyde in PBS. As a measure for cytoplasmic maturation, the distribution of cortical granules was assessed using fluorescein isothiocyanate-conjugated peanut agglutinin (FITC-PNA) staining as described by Izadyar et al. (1998) combined with 4',6-diamidino-2-phenylindole (DAPl; Sigma) staining to determine the stage of nuclear maturation (Izadyar et al. 1998). Slides were evaluated under an epifluorescence microscope and the oocytes were classified into three types on the basis of the distribution pattern of the cortical granules: type 1: large aggregates of cortical granules distributed over the entire cytoplasm; type 2: cortical granules localized in the cortical cytoplasm and distributed as individual particles as well as small aggregates; or type 3: cortical granules more or less evenly dispersed in the cortical cytoplasm aligning the oolemma.

In addition, 12 oocytes from the eCG group were investigated by transmission electron microscopy (TEM) to compare the ultrastructural location of cortical granules with the image obtained after FITC-PNA staining. In brief, the oocytes were embedded and cut into semi-thin $(2 \mu \mathrm{m}$ thickness) sections. All semi-thin sections (approximately 60 ) were stained with toluidine blue and analysed by light microscopy to determine the meiotic stage of each oocyte. Subsequently, the equatorial section of each oocyte was reembedded, cut into ultrathin sections (70 nm thickness), contrasted by lead citrate and uranyl acetate, and examined in a Philips CM 100 transmission electron microscope for cortical granule morphology. The meiotic stage and cortical granule distribution were evaluated as described by Hyttel et al. (1986).

\section{Blood sampling and radioimmunoassay of progesterone,} oestradiol and $\mathrm{LH}$

Blood samples were taken from the jugular vein into 
$10 \mathrm{ml}$ heparinized vacuum tubes, cooled immediately and centrifuged for $10 \mathrm{~min}$ at $500 \mathrm{~g}$ at $4^{\circ} \mathrm{C}$. Plasma was either stored at $-25^{\circ} \mathrm{C}$ or used immediately for rapid radioimmunoassay of $\mathrm{LH}$ and stored afterwards. Blood samples were taken once a day from day 0 (experimental day 12) of the synchronized cycle until 1 day before injection of rhFSH or eCG, and then at $6 \mathrm{~h}$ intervals until $24 \mathrm{~h}$ after injection of prostaglandin, subsequently at $1 \mathrm{~h}$ intervals until $72 \mathrm{~h}$ after prostaglandin treatment for the rapid $\mathrm{LH}$ radioimmunoassay to detect the $\mathrm{LH}$ surge, then at $6 \mathrm{~h}$ intervals until $96 \mathrm{~h}$ after prostaglandin treatment and, finally, once a day until day 7 after oestrus. Jugular catheters were used to collect blood samples at 10 min intervals for evaluation of pulsatile LH patterns.

Concentrations of progesterone and oestradiol were estimated by validated solid phase ${ }^{125}$ I radioimmunoassay methods (Coat-A-Count TKPG and TKE, respectively; Diagnostic Products Corporation, Los Angeles, CA) as described by Dieleman and Bevers (1987). The sensitivities were $0.05 \mathrm{ng} \mathrm{ml}^{-1}$ and $2 \mathrm{pg} \mathrm{ml}^{-1}$, the interassay coefficients of variation were $<11$ and $8.9 \%$, and the intra-assay coefficients of variation were 8 and $9 \%$, for progesterone and oestradiol, respectively.

For the rapid determination of LH concentrations, samples were estimated in triplicate by a rapid solid phase radioimmunoassay using bovine bLH-7981 for iodination and the antiserum of the standard assay (Dieleman et al., 1983). This rapid radioimmunoassay allowed determination of the $\mathrm{LH}$ concentration within $4 \mathrm{~h}$ after blood sampling. The $\mathrm{LH}$ concentration of blood samples during the LH surge was estimated afterwards by a standard assay as well, to validate the timing of the peak of the $\mathrm{LH}$ surge. The intra- and interassay coefficients of variation were $<9 \%$. The sensitivity was $0.4 \mathrm{ng} \mathrm{ml}^{-1} \mathrm{NIH}-\mathrm{LH}-\mathrm{B} 4$. Crossreactivity with eCG (highly purified eCG, PM23-2P; Intervet International BV) was $0.2 \%$.

\section{Data handling and statistical analyses}

All data are presented as mean \pm SEM. Student's $t$ test was used for most comparisons of the mean of two groups. Generalized Estimated Equation analysis (S-plus 2000; MathSoft, Inc., Cambridge, MA) was used for the analysis of time-dependent data, such as: (i) follicular growth; (ii) plasma oestradiol concentrations; and (iii) plasma progesterone concentrations. Data were considered significantly different at $P<0.05$.

The mean progesterone:oestradiol ratio in follicular fluid per follicle (Table 1) was calculated by taking the mean of the In values of the progesterone:oestradiol ratios and calculating this back again via $\mathrm{e}^{x}$.

The patterns of pulses in the $8 \mathrm{~h}$ profiles of $\mathrm{LH}$ were analysed according to Kooistra et al. (1999) by means of the Pulsar program developed by Merriam and Wachter (1982). The program identifies secretory peaks by height and duration from a smoothed baseline using the SD as a scale factor. The cut-off parameters G1-G5 of the Pulsar program

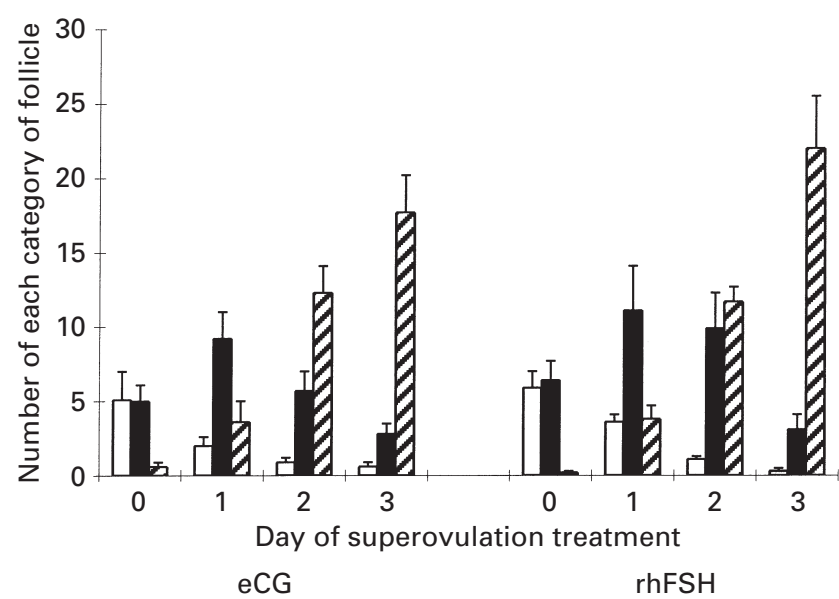

Fig. 1. Follicular response of heifers to stimulation with either equine chorionic gonadotrophin (eCG; $n=9$ ) or recombinant human FSH ( $\mathrm{rhFSH} ; n=9$ ). Numbers of small $(\square:<5 \mathrm{~mm}$ in diameter), medium ( $\mathbf{\square}: 5-8 \mathrm{~mm}$ in diameter) and large ( $\square:>8 \mathrm{~mm}$ in diameter) follicles are shown from day 0 (at the start of stimulation) to day 3 of superovulation treatment. Values are mean \pm SEM.

were set at $3.80,2.26,1.56,1.13$ and 0.83 times the assay SD as criteria for accepting peaks 1, 2, 3, 4 and 5 points wide, respectively. The smoothing time, a window used to calculate a running mean value omitting peaks, was set at $6.5 \mathrm{~h}$. The splitting cut-off parameter was set at 2.7 and the weight assigned to peaks was 0.01 . The $A, B$ and $C$ values of the Pulsar program, used to calculate the variance of the assay, were set at $A=4.81, B=-0.99$ and $C=6.16$. The values extracted from the Pulsar analyses included the number of peaks, mean peak amplitude, mean of the smoothed baseline, pulse frequency, mean pulse duration and the area under the curve.

\section{Results}

\section{Follicular development (sessions 1, 2 and 3)}

The number and ratio of small $(<5 \mathrm{~mm}$ in diameter), medium $(5-8 \mathrm{~mm}$ in diameter) and large $(>8 \mathrm{~mm}$ in diameter) follicles in heifers were not significantly different between heifers treated with $\mathrm{rhFSH}(n=9)$ or eCG $(n=9)$ at each day during superovulation treatment (Fig. 1). The number of large ( $>8 \mathrm{~mm}$ in diameter) follicles in both groups increased significantly during all days of gonadotrophin treatment $(P<0.05)$. At day 3 of stimulation treatment, the mean numbers of large follicles were $22.0 \pm 3.5$ and $17.7 \pm 2.5$ follicles for the rhFSH- and eCG-treated heifers, respectively; these values are not significantly different.

\section{Ovulation rate (sessions 1 and 2)}

Although the rhFSH treatment always resulted in occurrence of an LH surge, only three of the six heifers analysed showed multiple ovulations. In contrast, only four of the six eCG-treated heifers underwent a preovulatory LH 


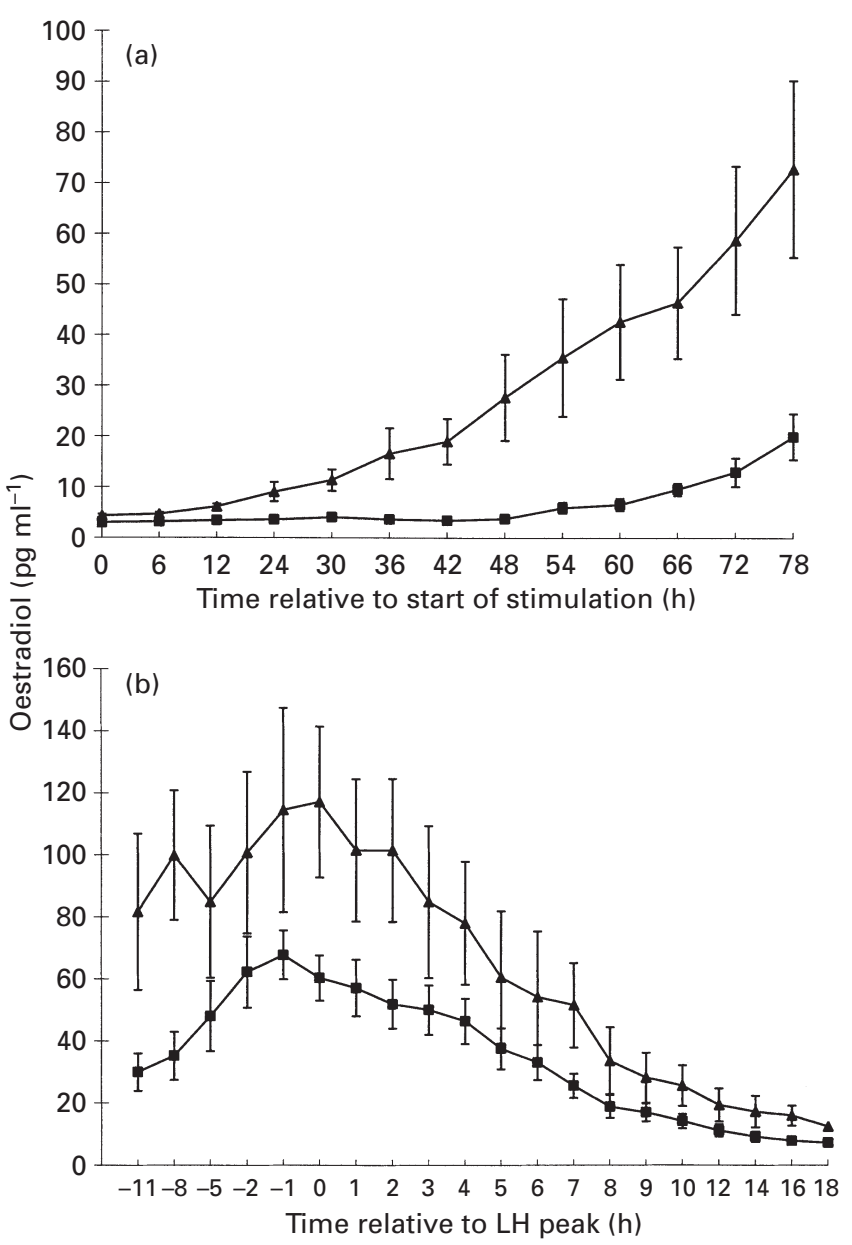

Fig. 2. Oestradiol concentrations in heifers during stimulation with either equine chorionic gonadotrophin (eCG; $\boldsymbol{\Delta} ; n=7$ ) or recombinant human $\mathrm{FSH}(\mathrm{rhFSH} ; \mathbf{\square} ; n=9$ ), (a) from the start of stimulation onwards and (b) relative to the time of the preovulatory $\mathrm{LH}$ surge. The two eCG heifers without an $\mathrm{LH}$ surge are not included. Values are mean \pm SEM.

surge, but these four heifers all showed multiple ovulations. As expected, no ovulations occurred in the two eCG-treated heifers without a preovulatory LH surge. The four eCGtreated heifers with an LH surge had a mean $11.8 \pm 2.3$ corpora lutea and $4.8 \pm 1.5$ unruptured follicles $>8 \mathrm{~mm}$ in diameter, whereas the six rhFSH-treated heifers had a mean $5.5 \pm 2.4$ corpus lutea and $12.2 \pm 3.6$ unruptured follicles. The difference in ovulation rate between the rhFSH- and eCG-treated heifers, although not significantly different, was due entirely to the three rhFSH-treated heifers that did not undergo multiple ovulations.

\section{Hormonal profiles (sessions 1, 2 and 3)}

All nine heifers treated with rhFSH underwent an $\mathrm{LH}$ surge that occurred a mean $47.1 \pm 1.5 \mathrm{~h}$ after prostaglandin injection. In the eCG-treated group, seven of nine heifers underwent an LH surge that occurred a mean $39.4 \pm 1.9 \mathrm{~h}$ after prostaglandin injection, which was significantly earlier than in the rhFSH group $(P<0.01)$. The amplitudes of the $\mathrm{LH}$ surge in the rhFSH $\left(19.6 \pm 1.3 \mathrm{ng} \mathrm{ml}^{-1}\right)$ and eCG $\left(15.9 \pm 2.3 \mathrm{ng} \mathrm{ml}^{-1}\right)$ groups were not significantly different. Furthermore, the mean amplitude of the LH surge of the three rhFSH heifers without multiple ovulations (19.4 \pm $1.7 \mathrm{ng} \mathrm{ml}^{-1}$ ) was not significantly different from that of the other six heifers (19.7 $\left.\pm 1.8 \mathrm{ng} \mathrm{ml}^{-1}\right)$.

During the superovulation treatment, the mean oestradiol concentration of the rhFSH group $(n=9)$ was significantly lower than that of the eCG-treated group from $12 \mathrm{~h}$ onwards ( $n=7$; Fig. 2a). The mean oestradiol concentration of the rhFSH-treated group was also significantly lower than that of the eCG-treated group at the days of the LH surge $\left(63.2 \pm 10.1\right.$ versus $110.8 \pm 28.0 \mathrm{pg} \mathrm{ml}^{-1}$, respectively; Fig. 2b). At the day of the LH surge, the oestradiol concentration in blood calculated per follicle of the rhFSH-treated heifers was approximately $50 \%$ of that of the eCG-treated heifers $\left(2.9 \pm 0.2\right.$ versus $5.6 \pm 0.6 \mathrm{pg} \mathrm{ml}^{-1}$, respectively). The oestradiol concentration profiles of the two eCG-treated heifers that did undergo an LH surge did not differ from those of the other eCG-treated heifers until the day corresponding to the day of the LH surge. Likewise, there was no significant difference in oestradiol production between the rhFSH-treated heifers with and without ovulations in the period up to the LH surge. In all eCG-treated heifers and the three rhFSH-treated heifers with multiple ovulations, the oestradiol concentration decreased from the day of the LH surge onwards (Fig. 2b; sessions 1 and 2). In contrast, an increase in oestradiol concentration was observed during the days after the LH surge in the three rhFSH-treated heifers without multiple ovulations before the subsequent decrease in oestradiol concentrations (Fig. 3; only rhFSH-treated heifers are shown).

At the start of the gonadotrophin treatment the eCGtreated heifers $(n=4)$ and rhFSH-treated heifers $(n=6)$ had similar progesterone concentrations $(4.2 \pm 0.4$ versus $4.2 \pm 0.4$; sessions 1 and 2, two eCG-treated heifers without an LH surge were not included). eCG but not rhFSH induced a significant increase in progesterone concentration at days 1 and 2 after the start of treatment, which reached $9.1 \pm 0.8 \mathrm{ng} \mathrm{ml}^{-1}$ for the eCG-treated heifers versus $5.1 \pm 0.3 \mathrm{ng} \mathrm{ml}^{-1}$ for the rhFSH-treated heifers at day 2 (the day of prostaglandin administration). This finding indicates that eCG has a stimulating effect on the corpus luteum. After the LH surge, the newly formed corpora lutea of the eCG-treated heifers also produced significantly higher progesterone concentrations than did the corpora lutea and luteinized follicles of the rhFSH-treated heifers from day 2 after ovulation onwards. The progesterone concentrations of the eCG- and rhFSH-treated heifers were $4.9 \pm 1.2$ versus $2.6 \pm 0.4 \mathrm{ng} \mathrm{ml}^{-1}$, respectively, at day 2 after ovulation, and $42.8 \pm 4.0$ versus $26.8 \pm 4.2 \mathrm{ng} \mathrm{ml}^{-1}$, respectively, at day 6 after ovulation. The rhFSH-treated heifers without multiple ovulations did not differ in progesterone production from the rhFSH-treated heifers that underwent multiple ovulations (results not shown). 

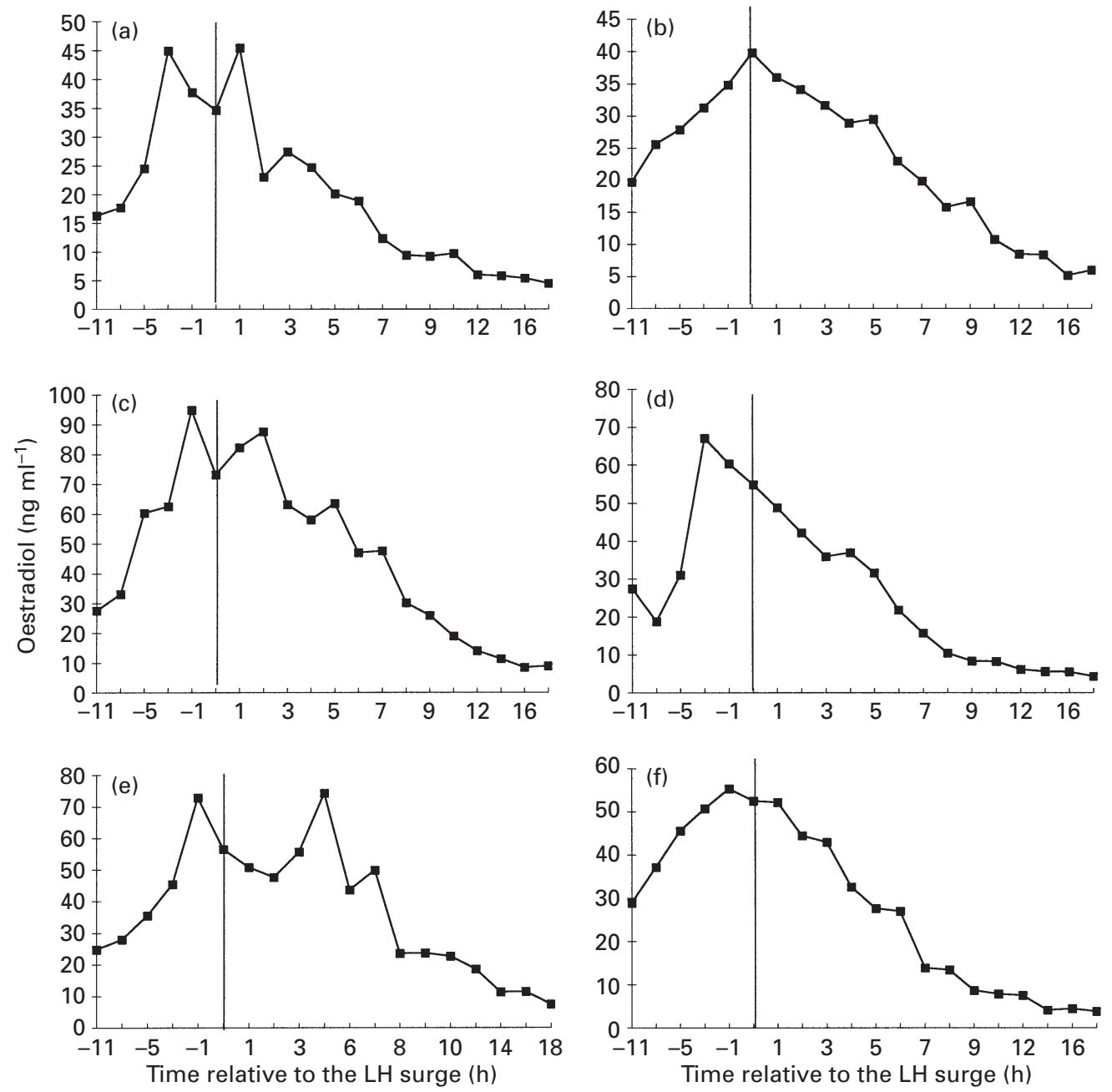

Fig. 3. Oestradiol concentrations of individual recombinant human FSH (rhFSH)-stimulated heifers around the time of the preovulatory LH surge (indicated with a vertical line). (a,c,e) Three heifers without multiple ovulations and $(b, d, f)$ three heifers with multiple ovulations.

\section{LH pulsatile patterns (session 2)}

The patterns of $\mathrm{LH}$ concentrations in three eCG-treated and three rhFSH-treated heifers $27-35 \mathrm{~h}$ after prostaglandin injection are shown (Fig. 4). The eCG-stimulated heifers had more LH pulses per heifer (mean $3.0 \pm 1.7$ per $8 \mathrm{~h}$ ) than did the rhFSH-stimulated heifers (mean $0.3 \pm 0.3$ per $8 \mathrm{~h}$ ). The rhFSH- and eCG-treated heifers had a similar baseline $\mathrm{LH}$ concentration $\left(0.51 \pm 0.01\right.$ and $0.45 \pm 0.02 \mathrm{ng} \mathrm{ml}^{-1}$, respectively) and a similar mean $\mathrm{LH}$ concentration (4.1 \pm 0.1 and $4.3 \pm 0.2$, respectively). It should be noted that two of the three eCG-treated heifers were closer to the preovulatory LH surge than the three rhFSH heifers (maximum of the LH surge at 37 and $38 \mathrm{~h}$ versus 41,44 and $49 \mathrm{~h}$ after prostaglandin injection, respectively). In these two eCG-treated heifers, the start of the preovulatory LH surge had already occurred during the second half of the sampling period. The third eCG-treated heifer, which had the highest number of $\mathrm{LH}$ pulses $(n=6)$ did not undergo an LH surge. The numbers of follicles $>8 \mathrm{~mm}$ in diameter on day 3 of superovulation treatment were 16,17 and 17 (mean 16.7 follicles) in the eCG-treated group and 22, 14 and 47 (mean 27.7 follicles) in the rhFSH-treated group; these numbers of follicles are not significantly different.

\section{Nuclear and cytoplasmic maturation of oocytes $24 \mathrm{~h}$ after the LH surge (session 3)}

At the time of ovariectomy ( $24 \mathrm{~h}$ after the preovulatory LH surge), no follicles had undergone ovulation in the rhFSH $(n=3)$ and eCG $(n=3)$ groups. The mean number of preovulatory sized follicles of rhFSH- $(25.7 \pm 8.7)$ and eCG- $(30.3 \pm 4.4)$ treated heifers was not significantly different. A total of 66 and 82 preovulatory follicles of $\mathrm{rhFSH}$ and eCG groups, respectively, were aspirated, from which $56(84.8 \%)$ and 65 (79.3\%) COCs were recovered, respectively. Oocytes for which the nuclear stage could not be detected due to technical reasons were excluded from the results (rhFSH group: two oocytes; eCG group: one oocyte). 

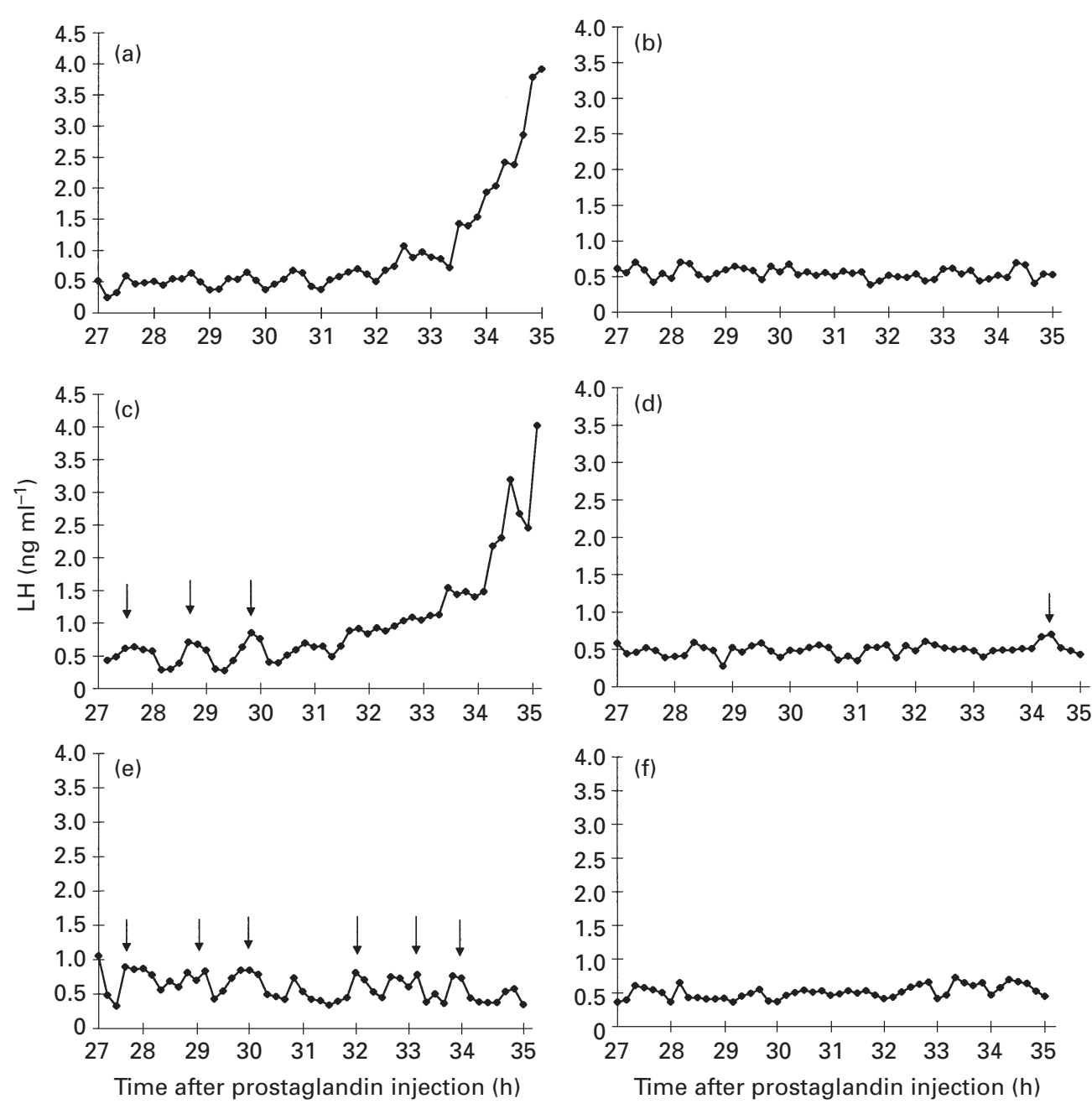

Fig. 4. LH pulsatile secretion patterns from blood samples collected at $10 \mathrm{~min}$ intervals during an $8 \mathrm{~h}$ period from 27 to $35 \mathrm{~h}$ after prostaglandin injection. Heifers were stimulated with either equine chorionic gonadotrophin (a,c,e: heifers 1, 2 and 3, respectively) or recombinant human FSH (b,d,f: heifers 4, 5 and 6, respectively). Arrows indicate LH pulses.

Large variation of cumulus expansion rates was observed for both the rhFSH-treated heifers (range 25-95\%) and the eCG-treated heifers (range 45-100\%) (Table 1). The relationships between stage of nuclear maturation and distribution patterns of cortical granules of the oocytes are summarized (Table 1). The rate of nuclear maturation was not significantly different between the $\mathrm{rhFSH}(63 \%, n=53)$ and eCG $(67 \%, n=33)$ groups. However, the percentage of metaphase II stage oocytes with type 3 cortical granule distribution was much lower in the rhFSH group (7\%) than in the eCG group (58\%). There was a correlation between the percentage of oocytes with an expanded cumulus and the percentage of oocytes in metaphase II for both the rhFSH and eCG groups. For example, for the rhFSH group, heifer 3, in which $95 \%$ of the COCs had an expanded cumulus, had a metaphase II rate of $95 \%$, whereas heifer 1, in which the cumulus expansion rate was $25 \%$, had a metaphase II rate of $29 \%$.

The transmission electron microscopy (TEM) study of 12 oocytes with an expanded cumulus from eCG-treated heifers confirmed the reliability of the FITC-PNA staining technique for assessing the distribution of the cortical granules. Eight of the twelve oocytes were in metaphase II, and these all showed a type 3-like distribution of the cortical granules. The other four oocytes were in metaphase I and had either a type $1(n=2)$ or type $3(n=2)$ distribution of the cortical granules. Therefore, the TEM observations were consistent with those after FITC-PNA staining.

\section{Progesterone and oestradiol concentrations of follicular fluids (session 3)}

The mean progesterone:oestradiol ratio per heifer is shown in combination with the oocyte maturation states (Table 1). All 66 follicles of the three rhFSH-treated heifers and all 52 follicles of two eCG-treated heifers (heifers 5 and 6) were progesterone-dominated (progesterone:oestradiol $>1$ ). However, in one eCG-treated heifer (heifer 4), $90 \%$ of 
M. Takagi et al.

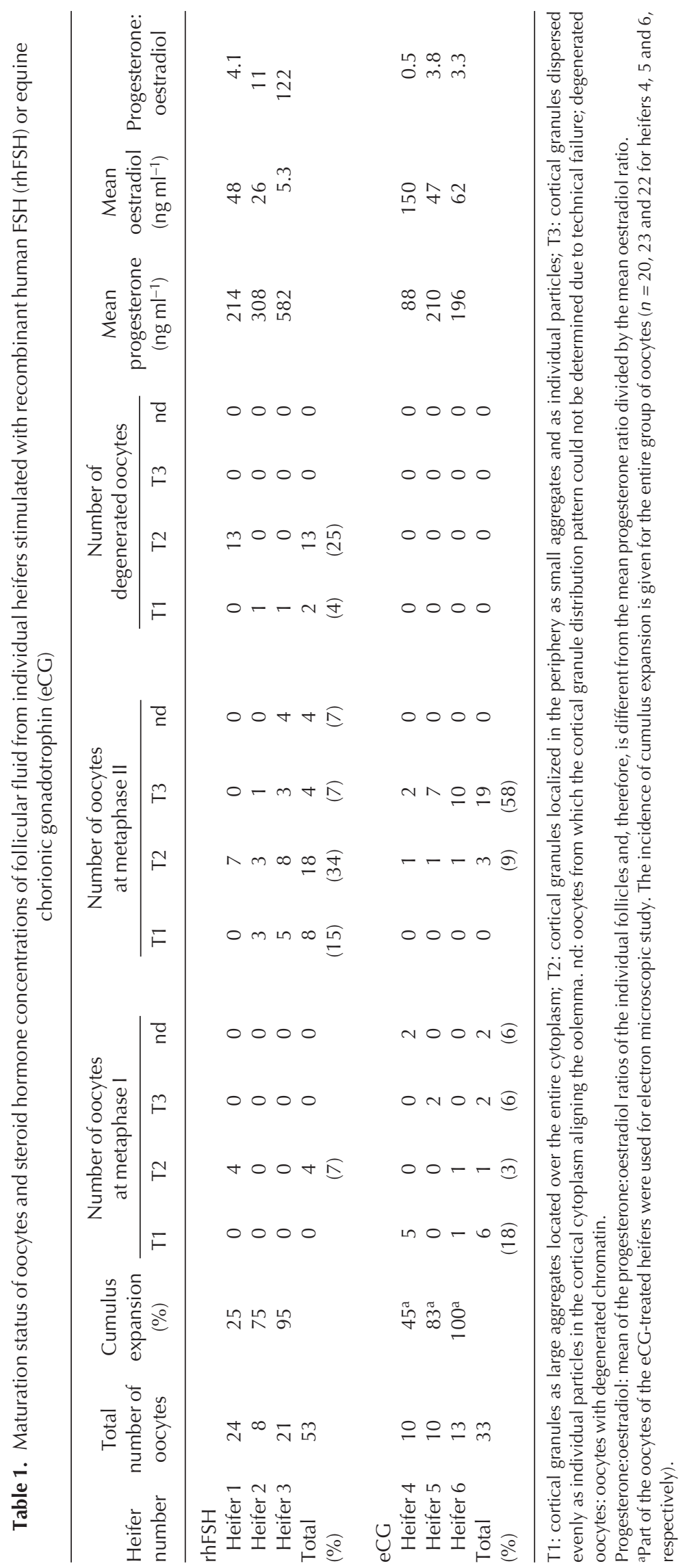


the follicles were oestradiol-dominated. In comparison to the other eCG heifers, heifer 4 had the lowest incidence of both cumulus expansion (45\%) and oocytes in metaphase II (three of ten oocytes). The mean oestradiol concentration of the follicular fluids of the rhFSH group $\left(28.1 \pm 3.5 \mathrm{ng} \mathrm{m}^{-1}\right.$; $n=66$ ) was significantly lower than that of the eCG group $\left(89.4 \pm 7.2 \mathrm{ng} \mathrm{ml}^{-1} ; n=82\right)$. In contrast, the mean progesterone concentration of the follicular fluids of the rhFSH group $\left(369.1 \pm 34.0 \mathrm{ng} \mathrm{m}^{-1} ; \quad n=66\right)$ was significantly higher than that of the eCG group $\left(160.7 \pm 17.7 \mathrm{ng} \mathrm{ml}^{-1}\right.$; $n=82$ ).

\section{Discussion}

The main aim of the present study was to investigate whether human $\mathrm{FSH}$ without contaminating $\mathrm{LH}$ can exert a normal superovulation response in cows. It was found that exogenous $\mathrm{LH}$ is not necessary for stimulation of growth of follicles beyond the stage of $8 \mathrm{~mm}$ in diameter and that these follicles are competent to induce an LH surge. However, the rhFSH-treated heifers had a higher incidence of aberrations in final follicular maturation. Three of six rhFSH-treated heifers did not undergo multiple ovulations and oocytes collected $24 \mathrm{~h}$ after the LH surge had a lower rate of cortical granule distribution at the periphery, which is indicative of less optimal cytoplasmic maturation.

The follicular response to eCG observed in the present study was similar to that reported previously (Bevers and Dieleman, 1987; Dieleman et al., 1989). Despite the equal sizes of the follicles in the eCG and rhFSH groups, the eCG-stimulated follicles produced much higher amounts of oestradiol than did the rhFSH-stimulated follicles. Oestradiol production in the eCG-treated heifers was a mean 4.5 times higher at $72 \mathrm{~h}$ after the start of stimulation and two times higher at the time of the LH surge than that of rhFSH-treated heifers. This finding is in line with earlier findings on comparisons between gonadotrophin preparations differing in LH activity (Aoyagi et al., 1987; Ben Jebara et al., 1994) and confirms the stimulating effect of exogenous LH activity on oestradiol production in bovine follicles (Webb et al., 1999). As oestradiol is the key factor for inducing the LH surge (Karsch et al., 1992), the earlier occurrence of the LH surge in the eCG group (39 $\pm 2 \mathrm{~h}$ after prostaglandin injection) compared with the rhFSH group (47 $\pm 2 \mathrm{~h}$ after prostaglandin injection) is probably a direct consequence of the higher oestradiol concentration in the eCG-treated heifers. The increase in progesterone concentration on days 1 and 2 after eCG stimulation but not after rhFSH stimulation is also probably due to the $\mathrm{LH}$ activity, which stimulates follicles to produce more oestradiol and cyclic corpora lutea to produce more progesterone. This effect of LH activity in gonadotrophin preparations has been described previously by Aoyagi et al. (1987) and Ben Jebara et al. (1994). It is remarkable that after ovulation the newly formed corpora lutea in the eCGtreated heifers have a higher progesterone-producing activity than the corpora lutea in the rhFSH-treated heifers.
This finding indicates that the eCG-stimulated follicles either contained more follicular cells that could luteinize or that the corpora lutea have a higher progesterone production per luteinized cell.

Gonadotrophin stimulation is known to result in a higher incidence of asynchrony of: (i) the maturation state of the follicle versus its oocyte (de Loos et al., 1991); and (ii) the maturation state of the nucleus versus that of the cytoplasm of the oocyte (Hyttel et al., 1986; Assey et al., 1994). The relatively high variations in steroid concentrations in follicular fluid and maturation status of the oocytes observed in the present study are in agreement with this. The finding that only $7 \%$ of the oocytes of the rhFSH-treated heifers had a type III cortical granule distribution points clearly to a less optimal cytoplasmic maturation in most of the follicles in this treatment group. The less optimal oocyte maturation in the rhFSH group was not related to an aberrant ratio of progesterone:oestradiol in the follicular fluid, which was $>1$ in all large follicles; in addition, it was not related to the proportion of oocytes with an expanded cumulus.

Experiments in non-stimulated cows have demonstrated that $\mathrm{LH}$ is essential for follicular growth beyond $8 \mathrm{~mm}$ in diameter (Gong et al., 1996). Obviously, the rhFSHstimulated heifers had sufficient endogenous LH activity to sustain the growth of a large number of follicles beyond $8 \mathrm{~mm}$ in diameter. However, the frequency of LH pulses was very low in the rhFSH-treated heifers and lower than that of the eCG-treated heifers. In the present study, the LH pulses were measured in a fixed time period after prostaglandin administration, which happened to be closer to the $\mathrm{LH}$ surge in two of the three eCG-treated heifers than in the three rhFSH-treated heifers. Therefore, the possibility that the LH pulsatility increased in the rhFSH-treated heifers in the period closer to the $\mathrm{LH}$ surge cannot be excluded totally. However, the highest number of $\mathrm{LH}$ pulses was found in the eCG-treated heifer that did not undergo an $\mathrm{LH}$ surge. Downregulation of the preovulatory LH pulses by gonadotrophin stimulation has been demonstrated in several studies (Bevers et al., 1989; Ben Jebara et al., 1994; Roberge et al., 1995; Price et al., 1999; Gosselin et al., 2000). Consistent with our results, this downregulation was found more apparent when relatively pure FSH preparations were used instead of eCG (Ben Jebara et al., 1994). At least in unstimulated cows, downregulation of the preovulatory LH pulses has been correlated with failures in ovulation (Roche et al., 2000). The preovulatory LH pulses have also been proposed to induce the maturation-like changes in the COC that already start in the period preceding the LH surge (Hyttel et al., 1997). In gonadotrophin-stimulated cows, the LH pulse frequency during preovulatory follicular development is positively correlated with the number of corpora lutea and total number of embryos (Roberge et al., 1995). The mechanism by which gonadotrophin stimulation suppresses the LH pulsatility is still not known. Our results confirm those of Gosselin et al. (2000) that if an ovarian factor is involved in the downregulation of $\mathrm{LH}$ 
pulsatility, it is a compound other than oestradiol. The exact role of the preovulatory LH pulses for preovulatory follicular development is poorly understood and it is also unclear whether this role can be replaced by administration of a constant level of extraneously supplied LH.

The lack of ovulations in three of six rhFSH-treated heifers and the aberrant oocyte maturation in all rhFSHtreated heifers might also be related to an aberrant expression of follicular LH receptors. An indication for this is that all three rhFSH heifers without multiple ovulations reacted with a transient increase in the oestradiol concentration during the days after the LH surge, although the oestradiol concentration normally decreases rapidly after the LH surge (Bevers and Dieleman, 1987). However, these heifers underwent a similar progesterone production in response to the LH surge as the rhFSH heifers with multiple ovulations, indicating that $\mathrm{LH}$ receptors were present within the large follicles. However, the increase in oestradiol concentration indicates that at least some of the granulosa cells of some follicles did not luteinize, which might point to an absence of $\mathrm{LH}$ receptors on these aberrantly reacting granulosa cells. LH receptors are normally first expressed in granulosa cells in follicles reaching a size of $8 \mathrm{~mm}$ in diameter (Bao et al., 1997). This process might be disturbed in rhFSH-stimulated heifers.

Using recombinant $\mathrm{FSH}$ of bovine origin for stimulation of cattle, Wilson et al. (1993) found an embryo yield similar to that of pituitary extracts. It can be questioned whether a suboptimal dose of rhFSH was used in the present study. Owing to the limited amounts of rhFSH available, dose-response studies could not be applied. The different ways of calculation of the FSH units do not allow comparison of the dose of FSH used in the present study with that of Wilson et al. (1993). However, the good follicular response of the rhFSH heifers without symptoms of hyperstimulation gives a strong indication that the chosen dose was appropriate. Furthermore, the risk of hyperstimulation has been reported to be much lower for $\mathrm{FSH}$ preparations with a low LH activity (McGowan et al., 1985; Pawlyshyn et al., 1986; Gonzalez et al., 1990). Wilson et al. (1993) collected more than two ova or embryos per cow after stimulation with doses of rbFSH ranging from 4 to $64 \mathrm{mg}$. In concordance with our data, highly purified pig FSH isolated from pituitary glands has also been reported to exert poor superovulation responses, which could be overcome by adding a minimal amount of LH (Schmidt et al., 1988; Herrler et al., 1991). The different superovulation responses of rbFSH and rhFSH compared with highly purified pig FSH raise the interesting question that this might be due to differences among species. Bovine, human and pig FSH might differ in binding affinity or activation of bovine $\mathrm{FSH}$ and $\mathrm{LH}$ receptors or in degradation time in cows.

In conclusion, the suboptimal results after rhFSH stimulation might be best explained with the following model. The rhFSH-stimulated heifers have endogenous LH activity to sustain the growth of a large number of follicles beyond $8 \mathrm{~mm}$ in diameter. However, the combination of a complete lack of exogenous LH with a severe suppression of preovulatory LH pulses leads to suboptimal follicular development so that the follicles do not respond optimally to the $\mathrm{LH}$ surge. This process might be mediated by impaired expression of $\mathrm{LH}$ receptors on the granulosa cells. Finally, this process results in a disturbed cytoplasmic maturation of the oocytes in the main part of the follicles and an impaired ovulation process in some of the heifers. In other gonadotrophin preparations the downregulation of the LH pulsatility might be compensated for by administration of extraneous LH activity which is lacking in rhFSH. These results lead to the question of whether pure $\mathrm{FSH}$ of human, bovine and pig origin exerts different effects in cattle. In addition, the stimulation of cattle with rhFSH might provide a useful model for further basic research on follicular development, oocyte maturation and ovulation in cattle, which might lead to more insight into ovarian dysfunction of humans, such as luteinized unruptured follicles.

M. Takagi was supported financially by a grant from the Ministry of Education, Science and Culture of Japan. P. J. M. Hendriksen was supported by Holland Genetics (Arnhem, The Netherlands) and the European Union. Human recombinant FSH was kindly supplied by R. G. Hanssen, Organon, Oss, The Netherlands. The authors would like to thank D. M. Blankenstein for assistance and performance of the radioimmunoassay hormone analyses, H. T. M. van Tol and E. Zeinstra for assistance during oocyte collection and J. C. M. Vernooy for the statistical analyses. The authors would also like to thank the animal caretakers and surgery assistants for management and surgical preparation of the animals.

\section{References}

Aoyagi Y, Iwazumi Y, Wachi H, Kweon OK, Takahashi Y, Kanagawa H, Miyamoto A, Umezu M and Masaki J (1987) Studies on superovulation with PMSG and FSH in cows - hormone levels of plasma steroid and results of embryo recovery Japan Journal of Animal Reproduction 33 167-172

Assey RJ, Hyttel P, Roche JF and Boland M (1994) Oocyte structure and follicular steroid concentrations in superovulated versus unstimulated heifers Molecular Reproduction and Development 39 8-16

Bao B, Garverick HA, Smith GW, Smith MF, Salfen BE and Youngquist RS (1997) Changes in messenger ribonucleic acid encoding luteinizing hormone receptor, cytochrome P450-side chain cleavage, and aromatase are associated with recruitment and selection of bovine ovarian follicles Biology of Reproduction 56 1158-1168

Beckers JF (1987) Isolation and use of a porcine FSH to improve the quality of superovulation in cattle Theriogenology 27213 (Abstract)

Ben Jebara MK, Carriere PD and Price CA (1994) Decreased pulsatile LH secretion in heifers superovulated with eCG or FSH Theriogenology 42 685-694

Bevers MM and Dieleman SJ (1987) Superovulation of cows with PMSG: Variation in plasma concentrations of progesterone, oestradiol, LH, cortisol, prolactin and PMSG and in number of preovulatory follicles Animal Reproduction Science 15 37-52

Bevers MM, Dieleman SJ, van Tol HTM, Blankenstein DM and van den Broek J (1989) Changes in pulsatile secretion patterns of LH, FSH, progesterone, androstenedione and oestradiol in cows after superovulation with PMSG Journal of Reproduction and Fertility 87 745-754

Boland MP, Goulding D and Roche JF (1991) Alternative gonadotrophins for superovulation in cattle Theriogenology 35 5-17 
Bungartz L and Niemann H (1994) Assessment of the presence of a dominant follicle and selection of dairy cows suitable for superovulation by a single ultrasound examination Journal of Reproduction and Fertility $101583-591$

Callesen H, Greve T and Hyttel P (1986) Preovulatory endocrinology and oocyte maturation in superovulated cattle Theriogenology 25 71-86

Callesen H, Greve T and Hyttel P (1987) Premature ovulations in superovulated cattle Theriogenology 28 155-166

de Loos FAM, Bevers MM, Dieleman SJ and Kruip ThAM (1991) Follicular and oocyte maturation in cows treated for superovulation Theriogenology 35 537-546

Dieleman SJ and Bevers MM (1987) Effects of monoclonal antibody against PMSG administered shortly after the preovulatory LH surge on time and number of ovulations in PMSG/PG-treated cows Journal of Reproduction and Fertility $\mathbf{8 1}$ 533-542

Dieleman SJ, Kruip ThAM, Fontijne P, de Jong WHR and van der Weyden GC (1983) Changes in oestradiol, progesterone and testosterone concentrations in follicular fluid and in the micromorphology of preovulatory bovine follicles relative to the peak of luteinizing hormone Journal of Endocrinology 97 31-42

Dieleman SJ, Bevers MM, Wurth YA, Gielen JTh and Willemse AH (1989) Improved embryo yield and condition of donor ovaries in cows after PMSG superovulation with monoclonal anti-PMSG administered shortly after the preovulatory LH peak Theriogenology 31 473-487

Donaldson LE (1984a) Embryo production in superovulated cows: transferable embryos correlated with total embryos Theriogenology 21 $517-524$

Donaldson LE (1984b) Effect of age of donor cows on embryo production Theriogenology 21 963-967

Donaldson LE and Ward DN (1986) Effects of luteinising hormone on embryo production in superovulated cows Veterinary Record 119 625-626

Frydman R, Howles CM and Truong F (2000) A double-blind, randomized study to compare recombinant human follicle stimulating hormone (FSH; Gonal-F) with highly purified urinary FSH (Metrodin) HP) in women undergoing assisted reproductive techniques including intracytoplasmic sperm injection The French Multicentre Trialists Human Reproduction 15 520-525

Gong JG, Campbell BK, Bramley TA, Gutierrez CG, Peters AR and Webb R (1996) Suppression in the secretion of follicle-stimulating hormone and luteinizing hormone and ovarian follicle development in heifers continuously infused with a gonadotropin-releasing hormone agonist Biology of Reproduction $\mathbf{5 5}$ 68-74

Gonzalez A, Lussier JG, Carruthers TD, Murphy BD and Mapletoft RJ (1990) Superovulation of beef heifers with follitropin: a new FSH preparation containing reduced LH activity Theriogenology 33 519-529

Gosselin N, Price CA, Roy R and Carrière PD (2000) Decreased LH pulsatility during initiation of gonadotropin superovulation treatment in the cow: evidence for negative feedback other than estradiol and progesterone Theriogenology 54 507-521

Hasler JF, McCauley AD, Schermerhorn EC and Foote RH (1983) Superovulatory responses of Holstein cows Theriogenology 19 83-99

Herrler A, Elsaesser F, Parvizi N and Niemann H (1991) Superovulation of dairy cows with purified FSH supplemented with defined amounts of $\mathrm{LH}$ Theriogenology 35 633-643

Hyttel P, Callesen H and Greve T (1986) Ultrastructural features of preovulatory oocyte maturation in superovulated cattle Journal of Reproduction and Fertility $\mathbf{7 6}$ 645-656

Hyttel P, Fair T, Callesen H and Greve T (1997) Oocyte growth, capacitation and final maturation in cattle Theriogenology 47 23-32

Inaba T, Mori J, Ohmura M, Kato Y, Tomizawa K, Kato T, Ihara T, Sato I and Ueda S (1997) Baculovirus-insect cell production of bioactive porcine FSH Theriogenology 47 491-499

Izadyar F, Hage WJ, Colenbrander B and Bevers MM (1998) The promotory effect of growth hormone on the developmental competence of in vitro matured bovine oocytes is due to improved cytoplasmic maturation Molecular Reproduction and Development 49 444-453

Karsch FJ, Moenter SM and Caraty A (1992) The neuroendocrine signal for ovulation Animal Reproduction Science 28 329-341
Keene JL, Matzuk MM, Otani T, Fauser BCJM, Galway AB, Hsueh AJW and Boime I (1989) Expression of biologically active human follitropin in Chinese hamster ovary cells Journal of Biological Chemistry 264 4769-4775

Kooistra HS, Okkens AC, Bevers MM, Popp-Snijders C, van Haaften B, Dieleman SJ and Schoemaker J (1999) Bromocriptine-induced premature oestrus is associated with changes in the pulsatile secretion pattern of follicle-stimulating hormone in beagle bitches Journal of Reproduction and Fertility 117 387-393

Lerner SP, Thayne WV, Baker RD, Henschen T, Meridith S, Inskeep EK, Dailey RA, Lewis PE and Butcher RL (1986) Age, dose of FSH and other factors affecting superovulation in Holstein cows Journal of Animal Science 63 176-183

McGowan MR, Braithwaite M, Jochle W and Mapletoft RJ (1985) Superovulation of beef heifers with pergonal (HMG): a dose response trial Theriogenology 24 173-184

Mannaerts BMJL, de Leeuw R, Geelen J, Van Ravenstein A, Van Wezenbeek P, Schuurs A and Kloosterboer L (1991) Comparative in vitro and in vivo studies on the biological characteristics of recombinant human follicle-stimulating hormone Endocrinology 129 2623-2630

Merriam GR and Wachter KW (1982) Algorithms for the study of episodic hormone secretion American Journal of Physiology 243 310-318

Monniaux D, Mariana JC and Gibson WR (1984) Action of PMSG on follicular population in the heifer Journal of Reproduction and Fertility $70243-253$

Murphy BD, Mapletoft RJ, Manns J and Humphrey WD (1984) Variability in gonadotrophin preparations as a factor in the superovulatory response Theriogenology 21 117-125

Out HJ, Reimitz PE and Coelingh Bennink HJT (1998) A prospective, randomized study to assess the tolerance and efficacy of intramuscular and subcutaneous administration of recombinant follicle-stimulating hormone (Puregon*) Fertility and Sterility 69 Supplement 134-39

Pawlyshyn V, Lindsell CE, Braithwaite M and Mapletoft RJ (1986) Superovulation of beef cows with FSH-P: a dose-response trial Theriogenology 25179 (Abstract)

Price CA, Carriere PD, Gosselin N, Kohram H and Guilbault LA (1999) Effects of superovulation on endogenous LH secretion in cattle, and consequences for embryo production Theriogenology 51 37-46

Recombinant Human FSH Product Development Group (1998) Recombinant follicle stimulating hormone: development of the first biotechnology product for the treatment of infertility Human Reproduction Update 4 862-881

Roberge S, Rieger D and Rawlings NC (1995) Periovulatory LH, FSH and steroid hormone profiles in superovulated and unstimulated Holstein heifers Theriogenology 44 59-70

Roche JF, Mackey D and Diskin MD (2000) Reproductive management of postpartum cows Animal Reproduction Science 60-61 703-712

Schmidt M, Greve T and Callesen H (1988) Superovulation of cattle with FSH containing standardized LH amounts ICAR Congress Proceedings 191-193

van Wezenbeek P, Draaijer J, van Meel F and Olijve W (1990) Recombinant follicle-stimulating hormone I. Construction, selection and characterization of a cell line. In From Clone to Clinic, Developments in Biotherapy, Vol. I, pp 245-251. Kluwer Academic, Dordrecht, The Netherlands

Vos PLAM, de Loos FAM, Pieterse MC, Bevers MM and Dieleman SJ (1994) Evaluation of transvaginal ultrasound-guided follicle puncture to collect oocytes and follicular fluids at consecutive times relative to the preovulatory LH surge in PMSG/PG-treated cows Theriogenology 41 829-840

Webb R, Gosden RG, Telfer EE and Moor RM (1999) Factors affecting folliculogenesis in ruminants Animal Science 68 257-284

Wilson JM, Jones AL, Moore K, Looney CR and Bondioli KR (1993) Superovulation of cattle with a recombinant-DNA bovine follicle stimulating hormone Animal Reproduction Science 33 71-82

Received 1 December 2000

First decision 22 January 2001

Accepted 26 February 2001. 